Est Ag 43 (2008) 489-506

\title{
Obispos, laicos y política según san Agustín
}

Los cuarenta años de existencia del Estudio Teológico Agustiniano de Valladolid representan un período de gran redimensionamiento del poder de la Iglesia católica en la vida política de países y regiones del mundo históricamente católicos, entre ellos Italia, Austria, Irlanda, Québec y naturalmente España, por nombrar sólo unos cuantos. En Italia, durante este período, la preeminencia del principal partido político católico, la Democracia Cristiana, ha disminuido mucho con respecto a otros partidos y movimientos políticos no aliados con la jerarquía eclesiástica; mientras que en otros lugares como Québec e Irlanda, los obispos no gozan ya de la relación acogedora con los políticos que tuvieron durante los años 1960 y 70 . No obstante, los últimos 40 años han sido testigos en estas naciones de una mayor confianza en la esfera política por parte de las conferencias episcopales nacionales. Los obispos, actuando individual y colectivamente, han expresado vehementemente su opinión acerca de diferentes temas morales, a menudo en oposición a las posiciones tomadas por los políticos católicos sobre estos temas, por ejemplo en el ámbito de la bioética y, últimamente, el de la inmigración. Se puede decir lo mismo de los obispos de las naciones occidentales donde los católicos son minoría, como en el Reino Unido y los Estados Unidos. Tomando parte en la discusión pública sobre estos temas, los obispos han recordado a los políticos católicos su obligación de apoyar la enseñanza de la Iglesia sobre diversos temas, tales como el aborto, y en ocasiones han amenazado con condenas e incluso -particularmente en los Estados Unidos- con sanciones eclesiásticas, incluida la prohibición de recibir la comunión, a menos que apoyaran la posición católica acerca de ciertos temas ${ }^{1}$.

Quiero centrarme en esta intervención en la relación entre obispos y políticos católicos. Quiero hacerlo porque el tema es actual hoy en día, tanto

${ }^{1}$ Sobre los textos básicos acerca de la negación de la comunión cf. CIC, cc. 915, 1331, 1332, 1722; Juan Pablo II, Ecclesia de Eucharistia, n. 37b; Congregación para el culto divino y la disciplina de los sacramentos, Redemptionis Sacramentum, n. 183. Ver también Edward N. 
en vuestro país como en el mío, pero también porque es actual en muchos de los países, si no en todos, en los que trabaja la Orden de San Agustín a lo largo del mundo. Específicamente quiero centrarme en la cuestión de cómo los obispos deben abordar con los políticos católicos la aplicación de principios éticos católicos en cuestiones sociales y políticas. Aquí, me refiero a la misión magisterial de los obispos, en la que públicamente fijan las enseñanzas morales católicas ${ }^{2}$, así como en sus responsabilidades episcopales de santificar y gobernar, bajo cuya autoridad amonestan e incluso sancionan a políticos católicos que, en el ejercicio de sus tareas públicas, rechazan o rehúsan aplicar las enseñanzas morales de mayor peso de la Iglesia, como en los casos de aborto y eutanasia ${ }^{3}$.

Planteo esta cuestión porque no es algo universalmente aceptado como evidente el hecho de que los obispos actúen adecuadamente cuando intentan coaccionar a los políticos católicos por medio de la amenaza de sanciones eclesiásticas. ¿Cuánta presión deben usar los obispos para persuadir a los políticos católicos para que gobiernen la sociedad civil de acuerdo con

Peters, Denial of the Eucharist to pro-abortion politicians: a case study, en Homiletic \& Pastoral Review, (October 1990) 28-32, 48-49. Sobre el debate en los Estados Unidos sobre la negación a dar la comunión a los políticos católicos pro-abortistas, cf. Cardenal Joseph Ratzinger, Memorandum enviado al Cardenal Theodore McCarrick y al obispo Wilton Gregory, Worthiness to Receive Holy Communion - General Principles, June 2004; Conferencia episcopal estadounidense, Catholics in Political Life, 14-19 June 2004; Cardenal Joseph Ratzinger, Letter to Cardinal Theodore McCarrick, 9 July 2004, http://www.usccb.org/comm/ archives/2004/04-133.htm (consultada el 16 de mayo de 2008). Acerca de estos documentos, cf. Raymond L. Burke, Canon 915: The Discipline Regarding the Denial of Holy Communion to Those Obstinately Persevering in Manifest Grave Sin, en Periodica 96 (2007) 3-58; para una perspectiva contraria, cf. Bishop Donald Wuerl, Faith, Personal Conviction and Political Life, en Origins 34 (2004) 40.

2 Acerca del oficio magisterial de los obispos en general, cf. Concilio Vaticano II, Lumen Gentium, nn. 20;24; 25; Christus Dominus, II, 1, 12. Respecto a la postura de la Iglesia sobre la autoridad política, que "debe ser siempre ejercida dentro de los límites del orden moral y dirigirse hacia el bien común", cf. Concilio Vaticano II, Gaudium et Spes n. 74; cf. también ibid., nn. 75-76.

3 Sobre la tarea de santificación y de gobierno de los obispos en general, cf. Concilio Vaticano II, Lumen Gentium n. 27; CIC, cc. 375, 391, 1311, 1318. Sobre aborto y eutanasia como crímenes graves cf. Juan Pablo II, Evangelium vitae, n. 73a: "Así pues, el aborto y la eutanasia son crímenes que ninguna ley humana puede pretender legitimar. Leyes de este tipo no sólo no crean ninguna obligación de conciencia, sino que, por el contrario, establecen una grave y precisa obligación de oponerse a ellas mediante la objeción de conciencia"; n. 90: los líderes civiles "tienen el deber de tomar decisiones valientes en favor de la vida, especialmente en el campo de las disposiciones legislativas [...] Pero nadie puede abdicar jamás de esta responsabilidad, sobre todo cuando se tiene un mandato legislativo o ejecutivo, que llama a responder ante Dios, ante la propia conciencia y ante la sociedad entera de decisiones eventualmente contrarias al verdadero bien común". 
el magisterio moral de la Iglesia sobre las cuestiones sociales? No intentaré responder a esta cuestión completamente, sino más bien ofrecer un análisis desde la experiencia de san Agustín. En esta conferencia expondré que Agustín nos ofrece la primera teoría en absoluto de formación de la conciencia política cristiana. Diciendo esto sugiero que Agustín fue la primera autoridad en proponer una vía a los políticos cristianos para pensar sobre los problemas éticos asociados a sus tareas oficiales de un modo coherente con $s u$ fe. Esto no quiere decir que Agustín fuera el primero en dirigirse a los oficiales públicos sobre ética política. Algunos escritores anteriores a él urgieron a los cristianos con responsabilidades públicas a adoptar particulares posiciones éticas, o a tomar parte en asuntos específicos con implicaciones morales (Ambrosio de Milán, por ejemplo, nos viene rápidamente a la memoria). No obstante, Agustín es el primero que ofrece una explicación coherente y teórica de cómo los políticos cristianos deben abordar las decisiones éticas.

Encontramos esta teoría en la epístola 155 de Agustín, la última de las tres cartas que escribió a Macedonio, el vicario imperial romano para África. Como vicario para África, Macedonio estaba obligado a hacer respetar la ley romana en la diócesis civil de África, por ejemplo, juzgando casos criminales que conllevaban la pena de muerte. Era católico y se remite a Agustín como padre espiritual ${ }^{4}$. En algún momento durante su breve mandato (413-414 d.C.), Agustín le escribe por primera vez, probablemente para pedir clemencia en favor de alguien que había sido condenado a muerte. No conservamos esa carta, ni conocemos los particulares del caso o de quién se trataba ${ }^{5}$. En esta carta Agustín ofrece también a Macedonio mandarle los tres primeros libros de La Ciudad de Dios. Macedonio le responde expresando su entusiasmo por leer los libros, pero por lo que respecta a la solicitud de clemencia, aduce que tales intervenciones por parte de los obispos no tienen nada que ver con la propia esfera de vida pública de éstos, que concierne a la religión ${ }^{6}$. Agustín responde a Macedonio con una segun-

\footnotetext{
4 Ver Agustín, ep. 154.1 (Macedonio a Agustín).

5 La carta de Agustín no ha llegado hasta nosotros, pero puede verse ep. 152.1 (Macedonio a Agustín: CSEL 44.393): "itaque sine mora quod, optabat, obtinuit. uerum quoniam extitit occasio, hoc ipsum, quantulumcumque est, quod admonitus indulsi, nolo sine mercede remanere." En una carta posterior, Macedono se refiere de nuevo a la clemencia deseada, ver Agustín, ep. 154.1 (Macedonio a Agustín: CSEL 44.428): "Miro modo afficior sapientia tua et in illis, quae edidisti, et in his, quae interveniens pro sollicitis mittere non grauaris. [...] proinde statim commendatis effectum desiderii tribui; nam sperandi uiam ante patefeceram." Ver también Posidio, Vita Augustini 20 (ed. A. Bastiaensen, pp. 182-184).

6 Ver Agustín, ep. 152.2-3 (Macedonio a Agustín).
} 
da carta (epístola 153) en la que defiende las bases religiosas para sus intervenciones y las de otros obispos en favor de quienes afrontan la pena capital. Con esta carta también envía los libros de La Ciudad de Dios que le había prometido. En un pasaje de esta carta, el obispo de Hipona asegura que la pena de muerte y otras formas de disciplina "tienen sus medidas, causas (causae), razones (rationes) y utilidades". Admite que "por temor a esas cosas se reprimen los malos y viven los buenos más tranquilamente entre los malos"7. Algunos estudiosos que comentan este pasaje lo interpretan como una aprobación por parte de Agustín de la necesidad de la pena de muerte, basándose en que ayuda a disuadir del crimen. Estos estudiosos concluyen que aunque Agustín defiende la legitimidad de las solicitudes por parte de los obispos de clemencia en favor de algunos criminales condenados a muerte, él claramente está a favor de la pena de muerte en ciertos casos ${ }^{8}$.

El razonamiento de Agustín se basa, en parte, en Romanos 13, 1-8, que justifica el recurso a la pena capital por parte de las autoridades civiles. Usa esta cita bíblica por entero, incluyendo lo siguiente:

"los príncipes no están para que les tema quien obra el bien, sino quien obra el mal. ¿Quieres no temer a la autoridad? Haz el bien y ella te alabará. Porque es servicio de Dios para ti con vistas al bien. Pero, si haces el mal, teme, ya que no en vano lleva la espada. Es ministro de Dios y vengador y castigador para aquel que obra el mal. Por ello aceptad la necesidad de la sumisión, no tan sólo por el castigo, sino también en conciencia" $(\mathrm{Rm} 13,3-5)^{9}$.

En sintonía con el punto de vista de Pablo tal y como él lo interpreta, Agustín asegura a Macedonio que la severidad mostrada por el vicario imperial aplicando la pena de muerte es beneficiosa para la sociedad y promueve la paz. La sociedad, razona Agustín, requiere para su seguridad que el pueblo tema el castigo ${ }^{10}$. Agustín, por tanto, insiste en que la intercesión de los obispos en favor de clemencia debe entenderse sólo en el sentido de

\footnotetext{
${ }^{7}$ Ver Agustín, ep. 153.16 (CSEL 44.414): "Nec ideo sane frustra instituta sunt potestas regis, ius gladii cognitoris, ungulae carnificis, arma militis, disciplina dominantis, seueritas etiam boni patris. habent ista omnia modos suos, causas, rationes, utilitates. haec cum timentur, et cohercentur mali, et quietius inter malos uiuunt boni,...”.

${ }^{8}$ Una ejemplo típico de este punto de vista es H. A. Deane, The Political and Social Ideas of St. Augustine, New York / London, Columbia University Press, 1963, pp. 138-139.

${ }_{10}$ Ver Agustín, ep. 153.19 (CSEL 44.417-418).

${ }^{10}$ Ver Agustín, ep. 153.16 (CSEL 44.414): “... uerum etiam non inutiliter etiam metu legum humana cohercetur audacia. ut et tuta sit inter inprobos innocentia et in ipsis inprobis, dum formidatio supplicio frenatur facultas, inuocato deo sanetur uoluntas".
} 
mitigar, no abrogar, la severidad de los jueces civiles respecto a las penas que imponen, incluyendo la pena de muerte ${ }^{11}$.

Si esto fuera todo lo que Agustín dijo a Macedonio acerca del tema, no habría discusión acerca de que su apoyo a la pena capital era nada menos que absoluto, incluso condicionado por un deseo de clemencia ocasional. Pero este no es el caso. Dos razonamientos, no uno, que atañen a la cuestión aparecen en la carta de Agustín a Macedonio. Además de su defensa de una pena de muerte aplicada con moderación y frecuentemente dispensada con misericordia, se encuentra otra posición diferente, que también se arraiga en el Nuevo Testamento, en la que Agustín duda de que la pena capital pueda ser alguna vez aplicada justamente. Crucialmente, en vista de los temas de interés más amplios de esta intervención, este razonamiento alternativo mira hacia la ciudad celeste como guía para las virtudes que deben determinar el trato de la autoridad civil hacia quienes actúan erróneamente en la ciudad terrena. Volveré a este argumento sobre las virtudes más adelante.

Como en el caso de su defensa de la pena capital que hemos visto anteriormente en esta carta, Agustín vuelve una vez más al Nuevo Testamento, esta vez para reforzar su argumento contra la pena de muerte. Primero, dice, está el propio ejemplo de misericordia de Dios, atestado por la Escritura. Dios, afirma Agustín, no limita su misericordia en este caso, sino que la extiende incluso a los reincidentes (citando Mt 5, 45); Rm 2, 4; Ps. 2, $12^{12}$ “ ¿Cuánto más debemos ser nosotros misericordiosos con aquellos que prometen la corrección, aunque ignoramos si harán lo que prometen?" pregunta Agustín a Macedonio ${ }^{13}$. Esta misericordia que las autoridades civiles muestran hacia los condenados por crímenes capitales es una virtud que debe ser modelada según la propia misericordia de Dios ${ }^{14}$. Agustín cita Jn 8,3-11, el pasaje de la mujer sorprendida en adulterio, para argumentar que sólo Cristo era capaz de juzgar a la mujer justamente, desde el momento en que sólo él estaba libre de pecado. Este es un argumento importante en el tratamiento general de Agustín sobre la pena capital, que repite siempre en

11 Ver Agustín, ep. 153.19 (CSEL 44.417): "Prodest ergo et seueritas uestra, cuius ministerio quies adiuuatur et nostra...".

12 Ver Agustín, ep. 153.7.

13 Ver Agustín, ep. 153.6 (CSEL 44.401): “... quanto magis nos in eos, qui correctionem promittunt et, utrum faciunt, quod promittunt, incerti sumus, misericordes esse debemus, ...". A. Coccia, L'umanità di sant'Agostino. La pena di morte e la tortura, en La città di vita, 17,1962, pp. 586-587, contempla este argumento como un contrapunto crucial al énfasis de Agustín en la ep. 153,16 sobre la obligación del magistrado de imponer el orden.

14 Ver Augustín, ep. 153.8 (CSEL 44.404): "Cum igitur super peccatores tanta sit patientia, tanta misericordia dei, ut in hac temporali uita moribus emendatis non damnetur in aeternum, $[\ldots]$ quales nos esse oportet homines erga homines, ...". 
sus escritos acerca del tema, pero que encuentra poco eco en la literatura especializada que se ocupa de esta postura agustiniana ${ }^{15}$. Su interés en mirar de cerca la condición moral de los jueces que deben juzgar en casos importantes -aparte de poner de relieve la similitud moral entre ellos y aquellos a quienes juzgan- es insistir en que virtudes tales como la justicia y la prudencia, pueden ser entendidas y practicadas sólo por parte de quienes son virtuosos. Agustín advierte a Macedonio de que aunque él anteriormente había llamado "bueno" al gobernador, "nadie es bueno sino sólo Dios" (cf. Mt 10, 18; Lc 18, 19) ${ }^{16}$. Las autoridades civiles, como todos los seres humanos, deben reconocer que lo que poseen de verdadera virtud proviene de Dios, el bien supremo. En consecuencia, la virtud les pertenece por gracia divina, no por naturaleza ${ }^{17}$.

Agustín es consciente de la tensión existente en esta carta entre esos dos argumentos diferentes que conciernen a la aplicación de la pena de muerte -una tensión que se encuentra reflejada en el Nuevo Testamento, por ejemplo entre $\mathrm{Rm} 13$ y Jn 8. Aun así permite que estas formas de razonar estén juntas sin negarse mutuamente. Por tanto se abstiene de argumentar que el ejemplo misericordioso de Cristo niegue a las autoridades civiles recurrir a la pena capital ${ }^{18}$. Por otra parte, aclara que intercediendo ocasionalmente en favor de los criminales condenados, los obispos no cuestionan, en principio, la moralidad de la pena de muerte. No obstante, Agustín también insinúa en su carta que los pasajes del Nuevo Testamento que exhortan a los cristianos a mostrar misericordia permiten a los gobernantes cristianos mitigar la fuerza de $\mathrm{Rm} \mathrm{13,} \mathrm{que} \mathrm{les} \mathrm{autoriza} \mathrm{a} \mathrm{aplicar} \mathrm{la}$ pena de muerte ${ }^{19}$. ¿Cómo cree, entonces, Agustín que las autoridades civi-

15 Ver, por ejemplo, Agustín, en. Ps. 50.8-9, s. 13.7-9, 302.14. Combès, Deane, y otros autores (citados más abajo en la nota 18) descuidan este aspecto de la interpretación de Agustín de la cita de Jn 8,3-11 en los textos en los que él trata de la pena capital.

16 Ver Agustín, ep. 153.12.

${ }^{17}$ Ver Agustín, ep. 153.13. Ver también id., ep. 155.2.El argumento de Agustín demuestra la influencia sobre su pensamiento de la controversia con los pelagianos, que es contemporánea a este intercambio epistolar.

18 En sus conclusiones de que la carta 153 constituye un rechazo por parte de Agustín de la moralidad de la pena de muerte, G. Combès, La doctrine politique de saint Augustin, Paris, Librairie Plon, 1927, pp. 188-192, especialmente 191-192; N. Blázquez, El patrocinio agustiniano de la pena de muerte, en Augustinus, 20,1975, pp. 253-296, e id., Pena de muerte y humanismo agustiniano, en Augustinus, 21, 1976, pp. 135-151; y A. Coccia, L'umanità di sant'Agostino..., pp. 586-597, especialmente pp.586-587, no tienen en cuenta adecuadamente el matiz del argumento de Agustín en los párrafos $\$ \S 16-19$.

19 Ver Agustín, ep. 153.16. He tratado este punto en R. Dodaro, Augustine of Hippo Between the Secular City and the City of God, en Augustinus Afer. Saint Augustin: africanite et 
les deben decidir si aplicar y cuándo la pena de muerte? Una clave especial para entender la aproximación de Agustín a esta cuestión se puede encontrar volviendo a su interpretación de Jn 8, 3-1120. Agustín indica el papel de Cristo que demuestra a los fariseos y a los escribas que los pasajes de la Escritura que obligan a ejecutar la pena capital pueden ser interpretados benignamente. Agustín está profundamente convencido de que tanto el Deuteronomio como el Levítico señalan la lapidación como castigo por adulterio, y que los fariseos y los escribas tienen en cuenta esos pasos bíblicos cuando buscan tender una trampa a Cristo para que condene a la mujer. Pero Agustín también sabe que Cristo nunca contradice directamente o abroga ninguna parte de la ley del Antiguo Testamento, incluidos los pasajes que obligan a la pena capital ${ }^{21}$. Cuando comenta en otros lugares Jn 8 en sus escritos, Agustín explica que Cristo fue capaz de mostrar misericordia con la adúltera sin anular aquellos preceptos de la Escritura porque, siendo la eterna sabiduría de Dios, comprende que la única intención divina tras aquellos preceptos era mostrar que es justo para la sociedad establecer penas para frenar la inmoralidad ${ }^{22}$. Cristo, por tanto, sabe cómo deben ser

universalité. Actes du colloque international, Alger-Annaba, 1-7 avril 2001, edited by P.-Y. Fux et al., Fribourg: Presses universitaires de Fribourg, 2003, 287-305.

20 Se debe notar, quizás, que Jn 7,53-8,3-11 no aparece en los manuscritos griegos más antiguos y mejores y que aún hoy no es aceptado por parte de la mayoría de los estudiosos como genuinamente joánico. No obstante, ha sido encontrado en muchos códices latinos disponibles en la época de Agustín, así como en la Vulgata de Jerónimo, y Agustín lo aceptó sin cuestionar su autenticidad y canonicidad. Ver U. Becker, Jesus und die Ehebrecherin: Untersuchungen zur Text- und Überlieferungsgeschichte von Joh. 7.53 - 8.11, Berlin, Toepelmann, 1963; y M.-F. Berrouard, Augustin et la péricope de la femme adultère, en Euvres de saint Augustin. Homélies sur l'évangile de saint Jean XVII-XXXIII, Paris, Desclée de Brouwer, 1969, pp. 857-860.

21 Ver Agustín, ep. 153.9 (CSEL 44.405): "ita nec legem inprobauit, quae huius modi reas iussit occidi, ...". Ver también, id., s. 13.4, Io. eu. tr. 33.5 (CCL 36.308): "Non dixit: Non lapidetur! ne contra legem dicere uideretur." El mismo argumento aparece en id., en. Ps. 50.8. Sobre el fondo del comentario a este Salmo y su relación a la posición de Agustín respecto a la pena de muerte, ver S. Poque, L'écho des évenéments de l'été 413 à Carthage dans la prédication de saint Augustin, en Homo spiritalis. Festgabe für L. Verheijen zu seinem 70. Geburtstag, ed. C. Mayer, Würzburg, Augustinus-Verlag, 1987, pp. 391-399. Poque confirma el intento de situar este comentario el 15 de julio de 413 propuesto con anterioridad por A.-M. La Bonnardière, Les Enarrationes in Psalmos prêchées par saint Augustin à l'occasion de fêtes de martyrs, en Recherches augustiniennes 7, 1971, pp. 73-104, at pp. 80-81. Es, por tanto, aproximadamente contemporáneo al intercambio epistolar de Agustín con Macedonio.

22 Ver Agustín, ep. 153.16 (CSEL 44.414): "nec ob aliud, quantum sapio, in ueteri testamento antiquorum temporibus prophetarum seuerior legis uindicta ferubat, nisi ut osterderetur recte iniquis poenas constitutas. ut, quod eis parcere noui testamenti indulgentia commonemur, aut remedium sit salutis, quo peccatis parcatur et nostris, aut commendatio mansuetudinis, ut per eos, qui parcunt, ueritas praedicata non tantum timeatur, uerum etiam diligatur". 
interpretados y aplicados los preceptos que obligan a poner en práctica la pena capital ${ }^{23}$. Al mismo tiempo, Agustín cree que las palabras y los hechos de Cristo tal y como se contienen en las Escrituras sirven de ejemplo para todos los cristianos. Por tanto, concluye que los preceptos éticos contenidos en las Escrituras deben ser interpretados por todas las autoridades civiles a través de la sabiduría que personifica Cristo ${ }^{24}$. Implícitamente, señala Agustín, Macedonio debería buscar adquirir de Cristo la sabiduría que le permitiría gobernar en modo coherente con la sabiduría y el ejemplo de Cristo. Concluye así su carta a Macedonio.

En su segunda respuesta a Agustín, Macedonio señala la aceptación del argumento de Agustín en defensa de los obispos que interceden en favor de los criminales condenados, y revela que ha concedido la clemencia que el obispo había pedido inicialmente. También felicita al obispo por el contenido de los tres primeros libros de La Ciudad de Dios y observa que la sabiduría de esos libros, si se busca, puede aliviar las cargas de quienes viven en el mundo presente, el saeculum ${ }^{25}$.

Llegamos ahora a la tercera y última carta a Macedonio (epístola 155). Es en esta carta donde encontramos la teoría de Agustín sobre la formación de la conciencia política. Agustín comienza expresando su gratitud por la clemencia otorgada por Macedonio, y dice del vicario imperial que "se aproxima a la ciudad celestial de Dios" y que "arde en deseos de ella", desde el momento en que también está "inspirado con un amor por la eternidad, la verdad y la caridad" ${ }^{\text {26 }}$. Claramente, Agustín alaba el amor de

23 Ver Agustín, en. Ps. 50.8, Io. eu. tr. 33.5.

24 Agustín aclara este punto en otros textos donde comenta Jn 8,3-11. Ver, por ejemplo, Io. eu. tr. 33.5 (CCL 36.308): "Quid ergo respondit Dominus Iesus? quid respondit ueritas? quid respondit sapientia? quid respondit ipsa cui calumnia parabatur iustitia." Ver también id., s. 13.5 (CCL 41.180): “... remansit peccatrix et saluator. Remansit misera et misericordia. [...] quia ille ei iudex remanserat qui erat sine peccato. [...] Illos a uindicta repressit conscientia, me ad subueniendum inclinat misericordia."

25 Ver Agustín, ep. 154.1 (Macedonio a Agustín), "Miro modo afficior sapientia tua et in illis, quae edidisti, et in his, quae interveniens pro sollicitis mittere non grauaris. [...] proinde statim commendatis effectum desiderii tribui; nam sperandi uiam ante patefeceram." Ver también ibid., \$2 (CSEL 44.429): “... ut ego anceps sim, quid in illis magis mirer, sacerdotii perfectionem, philosophiae dogmata, historiae plenam notitiam an facundiae iucunditatem, [...]. haec uero nostra praecepta et simplicis uerique dei mysteria praeter uitam perpetuam, quam purissimis uirtutibus pollicentur, etiam haec saecularia et necessario, quia nati sumus, euentura mitigare."

26 Ver Agustín, ep. 155.1 (CSEL 44.430): “... quod animum tuum caritate aeternitatis et ueritatis atque ipsius caritatis affectum diuinae illi caelestique rei publicae, cuius regnator est Christus et in qua sola semper beataque uiuendum est, si recte hic pieque uiuatur, agnosco inhiantem, uideo propinquantem eiusque potiundae amplector ardentem." Ver también ep. 
Macedonio por la caridad dada la clemencia que ha mostrado. Pero el énfasis que Agustín muestra en el amor por la virtud del vicario imperial señala su intención de retomar el tema con el que había concluido su carta anterior, a saber, que para alcanzar la verdadera sabiduría y lograr justas decisiones, los oficiales públicos deben llegar a ser sabios y justos, como Cristo es sabio y justo. En el mismo inicio de su carta Agustín cuenta a Macedonio que para adquirir esas virtudes debe gobernar poniendo sus ojos en el amor de Dios que pertenece a la ciudad celeste ${ }^{27}$. A lo largo del resto de la carta, Agustín explica este principio, y al hacerlo ofrece lo que yo he llamado la primera guía, en absoluto, para el establecimiento de una conciencia política cristiana.

Brevemente, lo que Agustín propone a Macedonio en la epístola 155 es que debe permitir que su ejercicio de las virtudes políticas -prudencia, templanza, fortaleza y justicia-sea transformado por las virtudes teológicas -fe, esperanza y caridad. Esta es la esencia de cómo cree Agustín que los oficiales públicos deban tomar sus decisiones éticas. Para Agustín la fe, la esperanza y la caridad actúan juntas para conducir al creyente más allá de las perspectivas limitadas y temporales de la ciudad terrena y llevarle a un conocimiento y a un amor más profundo de Dios. Como resultado de este amor profundo de Dios, la percepción cristiana de las obligaciones de la virtud política en este mundo cambia, algunas veces incluso radicalmente. En esta carta, Agustín subraya el proceso de esta transformación e insinúa alguna de sus consecuencias para la ética política. En este momento debo hacer mención a mi punto de vista, que he desarrollado detalladamente en otro lugar ${ }^{28}$, de que en muchos aspectos este proceso que Agustín describe en la epístola 155 es paralelo a la transformación de las virtudes políticas señalada por muchos filósofos neoplatónicos de la antigüedad tardía, entre ellos Porfirio, Macrobio y Marino. El hecho de que me parezca que Agustín en esta carta se mueve de acuerdo a los objetivos de estos pensadores neo-

155.17, donde Agustín dice de Macedonio que incluso aunque lleva la toga de un juez terrenal, tiene su mente ampliamente fijada en la comunidad celeste.

27 Ver Agustín, ep. 155.1 (CSEL 44.430): “... quod animum tuum caritate aeternitatis et ueritatis atque ipsius caritatis affectum diuinae illi caelestique rei publicae, cuius regnator est Christus et in qua sola semper beataque uiuendum est, si recte hic pieque uiuatur, agnosco inhiantem, uideo propinquantem eiusque potiundae amplector ardentem."

28 Ver R. Dodaro, Political and Theological Virtues in Augustine, Letter 155 to Macedonius, en Augustiniana 54 (2004) 431-474. 
platónicos refuerza mi opinión de que lo que intenta en la epístola 155 es formular una teoría de la conciencia política cristiana.

Miremos más de cerca el proceso de transformación que sirve como base de la teoría de Agustín. Comienza la carta 155 examinando la virtud de la esperanza. La esperanza, afirma Agustín, junto con la fe, enseña a los creyentes que la bendición que buscan para ellos mismos no se puede lograr en esta vida, sino que debe ser deseada en la vida futura, según la confianza en las promesas de Dios ${ }^{29}$. En general, para Agustín, la fe nos dice lo que debemos creer sobre Dios y sus promesas, y por tanto establece las bases para la esperanza; ambas son preparación para el amor de Dios ${ }^{30}$.

La relación de la esperanza con el amor también es importante para el argumento general de Agustín. Llega a ella observando que en el pasado, los filósofos no cristianos fracasaron en el intento por encontrar la bienaventuranza en esta vida, aunque la habían buscado ${ }^{31}$. Cristo, por otra parte, ha revelado que esta vida bienaventurada sólo es alcanzable después de la muerte, en la vida futura. Para Agustín, este es el significado del consejo paulino "alegres en la esperanza, pacientes en la tribulación" $(\mathrm{Rm} 12,12)^{32}$. Vuelve más tarde a la misma conclusión en esta carta cuando insiste en que el estadista cristiano debe gobernar prudente y justamente reconociendo lo que la virtud de la esperanza enseña: que el objetivo primario del gobierno no debe ser promover el desarrollo de la felicidad en esta vida terrena como un fin en sí mismo.

Esta es, quizás, la proposición fundamental de la teoría de Agustín. Vista superficialmente parece benigna y poco original. Pero los historiadores de la filosofía son conscientes de sus consecuencias de largo alcance. Cualquier ética política que postule que el gobierno debe estar para algo más que sim-

29 Ver Agustín, ep. 155.4 (CSEL 44.434): "Hoc piorum praemium est, cuius adipiscendi spe uitam istam temporalem atque mortalem, non tam delectabiliter quam tolerabiliter ducimus, et mala eius tunc bono consilio et diuino munere fortiter ferimus, cum bonorum aeternorum fideli dei promissione et fideli nostra exspectatione gaudeamus." Nótese la expresión "fideli nostra exspectatione" (= en nuestra fiel expectación) por la que Agustín enlaza la fe y la esperanza.

30 Para una discusión más profunda sobre la relación entre fe y esperanza, ver $\mathbf{M}$. Jackson, Faith, Hope and Charity and Prayer in St. Augustine, en Studia Patristica. Papers presented to the Tenth International Conference on Patristic Studies held in Oxford 1987, vol. 22, ed. E. A. Livingstone, Leuven, Peeters Press, 1989, pp. 265-270. Jackson observa que para Agustín, "la fe es la base de la esperanza que es una preparación para la comunión de amor con Dios" (p. 267, citando trin. 8.6).

31 Ver Agustín, ep. 155.2-3.

32 Ver Agustín, ep. 155.4 (CSEL 44.434): "ad hoc nos exhortatus apostolus Paulus ait: spe gaudentes, in tribulatione patientes (Rom 12:12). ad hanc spem exhortor per Iesum Christum dominum nostrum. hoc enim deus ipse magister ...". 
plemente para el establecimiento de la felicidad para sus súbditos en esta vida provoca fuertes, en ocasiones incluso duras, exigencias sobre las conciencias de la clase política dirigente. Agustín en la epístola 155 señala que es consciente de esas exigencias y de la diferencia radical que provocarán en Macedonio. Recuerda al vicario imperial que si no aceptara este principio, se arriesgaría a elevar la obtención de beneficios temporales, como la salud, la prosperidad y la paz, por encima de la conquista de beneficios eternos, como la bienaventuranza y la vida en Dios, que transcienden la muerte. Agustín mantiene que los estadistas corrompen sus virtudes políticas cuando entienden los objetivos de estas virtudes en el horizonte limitado y temporal de esta vida presente ${ }^{33}$. La esperanza, para Agustín, reorienta por tanto el objetivo de las virtudes políticas lejos de una preocupación exclusiva que asegura los beneficios temporales de la ciudad terrena hacia la consecución de la bienaventuranza que pertenece a la ciudad celestial. De este modo, la esperanza altera la concepción de las virtudes políticas del estadista. Citando el salmo 143(144), Agustín se hace eco del juicio que allí aparece acerca de que sólo quienes están fuera (filii alienorum) creen que Israel ha sido bendecida por su prosperidad material y su seguridad, sus silos llenos de grano, sus ganados cebados, su orden público. Israel, según el salmista, sabe, sin embargo, que "la nación es bienaventurada ya que Dios es su Señor"34.

Agustín lleva más allá su argumentación comparando las virtudes políticas tal y como son concebidas antes y después de su transformación por la fe, la esperanza y la caridad. Comienza definiendo las virtudes políticas como son entendidas generalmente en términos seculares. Por tanto, la prudencia es la virtud que guía al estadista cuando reflexiona sobre los asuntos humanos, la fortaleza le permite superar el miedo a sus enemigos, la templanza le lleva a evitar la corrupción, y la justicia le dirige a dar a cada uno lo que le corresponde. Estas son las virtudes políticas definidas según los parámetros clásicos, como se conocen de Platón en adelante ${ }^{35}$. Pero, para

33 Ver Agustín, ep. 155.10.

34 Ver Agustín, ep. 155.7 (CSEL 44.437-8), citando el Sal 143(144): 11-15.

35 Ver Agustín, ep. 155.10. Ver Platón, República IV. 427E-434D. Estas definiciones convencionales de las virtudes políticas pueden encontrarse también en autores estoicos. Ver, por ejemplo, Stoicorum Veterum Fragmenta, ed. H. von Arnim, Stuttgart, 1968, vol. 1, pp. $49-50$ (n. 200-201), vol. 3, pp. 63-72 (n. 262-294). El discurso de Cicerón sobre las virtudes en términos de una ética práctica útil para el gobierno es una fuente importante para Agustín. Ver Cicerón, De inuentione 2.159-167, De officiis, libro 1. Sigue siendo útil como guía para esta discusión $\mathrm{H}$. F. North, Canons and Hierarchies of the Cardinal Virtues in Greek and Latin Literature, en The Classical Tradition: Literary and Historical Studies in Honor of Harry Caplan, ed. L. Wallach, Ithaca, Cornell University Press, 1966, pp. 165-183. 
Agustín, estas definiciones también indican el modo en que estas virtudes son entendidas por el estadista que las considera sólo dentro del horizonte limitado y temporal de la vida presente, sin referencia a la vida eterna. Agustín entonces se pregunta cómo se practicarían estas virtudes en la ciudad celeste.

Afirma que en la vida futura las virtudes políticas no se conciben en términos de lucha contra ningún tipo de mal, como por el contrario se hace en la vida presente. Por tanto, en la ciudad celeste, la prudencia no estará ya obligada a juzgar entre el bien y el mal, porque el mal no existirá; la fortaleza no necesitará más afrontar los problemas valientemente, porque las dificultades mundanas no existirán; la templanza no luchará contra las pasiones, porque las pasiones no existirán; y la justicia no requerirá que la riqueza se use para asistir a los pobres, porque la pobreza y las necesidades materiales no existirán ${ }^{36}$. Como consecuencia, concluye que sólo existe una virtud en la ciudad eterna, a saber, el amor de Dios, que Agustín también denomina sabiduría (sapientia $)^{37}$. Pero añade que en la ciudad celeste esta virtud puede también identificarse con la prudencia, la fortaleza, la templanza y la justicia. En este momento indica cómo estas virtudes existen en la vida futura. Explica que el alma en el cielo actúa prudentemente cuando se adhiere a Dios como bien que nunca puede perder; actúa con fortaleza porque se aferra tenazmente a ese bien y no será apartada de él; actúa con templanza en el sentido en que se adhiere a este bien en modo puro, porque no puede corromperse ya; y actúa justamente porque es lo adecuado para ella aferrarse a este bien, al cual está subordinado merecidamente ${ }^{38}$. Todas las virtudes en el cielo representan por tanto diferentes aspectos del amor de Dios.

Tras señalar cómo aparecen las virtudes políticas en la ciudad celeste, Agustín propone que los creyentes deben proponerse practicar esas virtudes en la ciudad terrena tal y como existen en la ciudad celeste. Por tanto, la

36 Ver Agustín, ep. 155.12. Ver también en. Ps. 83.11. En trin. 14.12, Agustín señala el Hortensius de Cicerón como fuente de esta argumentación.

37 Ver Agustín, ep. 155.12. (CSEL 44.442): "una ibi uirtus erit, et idipsum erit uirtus praemiumque uirtutis, quod dicit in sanctis eloquiis homo qui hoc amat: mihi autem adhaerere deo bonum est (Ps 72[73]:28). haec ibi erit plena et sempiterna sapientia, eademque ueraciter uita iam beata: peruentio quippe est ad aeternum ac summum bonum, cui adhaerere in aeternum est finis nostri boni." Ver también en. Ps. 83.11.

38 Ver Agustín, ep. 155.12 (CSEL 44.442): "dicatur haec et prudentia, quia prospectissime adhaerebit bono quod non amittatur; et fortitudo, quia firmissime adhaerebit bono unde non auellatur; et temperantia, quia castissime adhaerebit bono ubi non corrumpatur; et iustitia, quia rectissime adhaerebit bono cui merito subiciatur." 
prudencia en esta vida debe consistir en elegir amar a Dios por encima de cualquier otra cosa; la fortaleza, en no separarse del amor a pesar de las dificultades; la templanza, en no permitir que ninguna tentación nos distraiga de él; y la justicia, en prevenir el orgullo de mantenernos alejados de él $^{39}$. Agustín, por tanto, redefine las virtudes políticas tal y como deben ser practicadas en la tierra de acuerdo con sus perfecciones en la ciudad celeste. Claramente, para él, las virtudes tal y como son practicadas en la ciudad celeste ofrecen modelos de cómo deben ser observadas en la época presente.

En otro movimiento significativo también en la epístola 155, Agustín sugiere que la fe, la esperanza y la caridad deben ser consideradas colectivamente bajo el nombre de "verdadera piedad" (uera pietas). En otros lugares de su producción literaria, Agustín define la "verdadera piedad" como el "conocimiento y el amor del verdadero Dios" 40 . Por tanto, según él, el principal objetivo del estadista cristiano cuando gobierna debe ser ayudar a sus súbditos a amar a Dios tanto como sea posible en esta vida. Este objetivo fundamental debe guiar todos sus esfuerzos para avanzar incluso en el bienestar temporal de sus súbditos, sea que busque asistir al pobre que sufre necesidades materiales sea que busque imponer disciplina a los criminales y enemigos que amenazan la seguridad pública ${ }^{41}$. Por tanto, revisando las

${ }^{39}$ Ver Agustín, ep. 155.13 (CSEL 44.443): “quamquam et in hac uita, uirtus non est nisi diligere, quod diligendum est; id eligere, prudentia est, nullius inde auerti molestiis fortitudo est, nullis inlecebris, temperantia est, nulla superbia iustitia est. quid autem eligamus quod praecipue diligamus, nisi quo nihil melius inuenimus. hoc deus est, cui si diligendo aliquid uel praeponimus, uel aequamus, nos ipsos diligere nescimus. tanto enim nobis melius est, quanto magis in illum imus, quo nihil melius est." Se compare este pasaje con una paralelo en trin. 14.12. Más adelante, en esta epístola, ep. 155.16 (CSEL 44.446), Agustín repite estas definiciones modificadas de las virtudes políticas, diciendo que cuando alguien tras una sobria discreción elige amar a Dios, es prudente; cuando no permite que la aflicción le detenga, es fuerte; cuando no permite que los placeres le desvíen, actúa con templanza; y cuando evita la altivez que le disuade de amar a Dios, es justo: "hoc qui sobria discretione eligit, prudens est; qui nulla hinc afflictione auertitur, fortis est, qui nulla alia delectatione, temperans est, qui nulla elatione, iustus est."

40 Ver, por ejemplo, Agustín, ciu. 10.3, ep. 140.45, ep. 155.2, 155.17, ep. 167.11. Ver también C. Mayer, "Pietas" und "vera pietas quae caritas est". Zwei Kernfragen der Auseinandersetzung Augustins mit der heidnischen Antike, en Augustiniana Traiectina. Communications présentées au Colloque International d'Utrecht 13-14 novembre 1986, ed. J. den Boeft and J. van Oort, Paris, Études augustiniennes, 1987, pp. 119-136.

41 Ver Agustín, ep. 155.12 (CSEL 44.441-2): 'si enim uirtutes quas accepisti, a quo acceperis sentiens, eique gratias agens, eas ad ipsius cultum etiam in tuis istis saecularibus honoribus conferas, tuaeque potestati subditos homines ad eum colendum exemplo tuae religiosae uitae, et ipso studio consulendi, seu fouendo seu terrendo erigas et adducas, nihilque aliud in eo quod per te securius uiuunt, uelis, nisi ut hinc illum promereantur, apud quem beate uiuent; et uerae illae uirtutes erunt ....". 
concepciones convencionales de las virtudes políticas, Agustín no da a entender que los oficiales públicos deban dejar a un lado la conquista de beneficios temporales para sus súbditos. Al contrario, propone que una vez que hayan entendido los objetivos de esas virtudes tal y como se encuentran en la ciudad celeste, sus expectativas sobre los beneficios que deben promover en la ciudad terrena se transformen.

Puede resultar útil en nuestro esfuerzo por entender cómo concibe Agustín las consecuencias que su teoría para la práctica política conlleva, volver a su breve mención sobre la paz en esta carta. Sugiere que cuando el estadista concibe la paz según su definición convencional, piensa sobre su objetivo en un sentido restrictivo como ausencia de sufrimiento. Pero cuando modifica su concepción de paz a través de la fe, la esperanza y la caridad, la considera como la promoción de la bienaventuranza en Dios ${ }^{42}$. Para Agustín, hay una diferencia sustancial entre estos dos modos de concebir la paz en la ciudad terrena.

Podemos quizás tener una idea más clara del modo en que Agustín considera que el estadista cristiano debe aplicar esta definición modificada de paz a partir de la epístola 138, escrita a un militar, Marcelino, justo dos años antes de la epístola 155. En esta carta Agustín esboza la teoría que más tarde expondrá plenamente en la epístola 155, de que la fe, la esperanza y la caridad transforman las virtudes políticas ${ }^{43}$. Destaca que la fe cristiana obliga a sus fieles a adoptar una cierta visión de la paz, que les exige armonizar los preceptos de la Escritura que les invitan a la no violencia con los preceptos, también de la Escritura, que permiten el uso de una cierta cantidad de fuerza para resistir el mal. (Hemos visto ya esta misma yuxtaposición de pasajes de la Escritura en la epístola 153 de Agustín a Macedonio en relación con la pena de muerte). Comentando acerca de la necesidad en $\mathrm{Rm}$ 12 de que los discípulos de Cristo no deben "devolver mal por mal" ( $\mathrm{Rm} 12$, 17) para que el bien pueda vencer el mal (cf. Rm 12, 21), Agustín plantea diversos puntos para la reflexión de Marcelino. En primer lugar, buscando superar el mal enemigo con la bondad, los oficiales cristianos deben querer

\footnotetext{
42 Ver Agustín, ep. 155.10 (CSEL 44.440-441): "si quaelibet, inquam, administratio tua, illis quas commemoraui instructa uirtutibus, hoc intentionis fine determinantur, ut homines secundum carnem nullas iniquas molestias patiantur; nec ad te existimas pertinere, quo istam quietem, quam praestare niteris, referant, id est (ut uerbis non ambiam) quomodo deum uerum, ubi est quietae uitae omnis fructus, colant, nihil tibi prodest ad uitam uere beatam tantus labor."

43 Ver Agustín, ep. 138.17 (CCL 44.144): “...cui nos ciues adsciscit fides, spes, caritas, ut, quam diu inde peregrinamur, feramus eos, si corrigere non ualemus, qui uitiis inpunitis uolunt stare rem publicam, ...".
} 
arriesgar la pérdida de algunos beneficios temporales de sus súbditos, tales como la seguridad acerca de los sufrimientos físicos. Él supone, no obstante, que haciendo esto, el cristiano ofrece a su enemigo un ejemplo de orden social alternativo, un modelo que premia con beneficios duraderos de justicia y de fe por encima de la consecución de ventajas temporales de orden militar o económico ${ }^{44}$. De este modo, también, los cristianos resisten la tentación de ser arrastrados lejos de su fe y evitan desear las ventajas mundanas que sus enemigos sí desean ${ }^{45}$.

No obstante, continúa Agustín, puede ser que este ejemplo no alcance su pretendido fin, y se requiera la fuerza para someter al enemigo, por tanto es lícito para los cristianos encontrar modos para responder según el modo militar sin ceder al deseo de venganza ${ }^{46}$. Hacer esto requiere que los líderes políticos reflexionen en sus conciencias acerca de la importancia de la paciencia cuando se afronta el sufrimiento y de la benevolencia hacia el enemigo, incluso mientras están ocupados en esfuerzos militares para doblegar las amenazas del enemigo. Esta tensión exige que los líderes cristianos limiten la violencia que emplean contra el enemigo al mínimo absoluto requerido para prevenir que el enemigo inflija mayor daño. Agustín concluye esta reflexión sugiriendo, "si esta república terrena mantuviese los preceptos cristianos, las mismas guerras no se llevarían a cabo sin benevolencia, pues se miraría más fácilmente por los vencidos con vistas a una sociedad tranquila, pacificada en la piedad y la justicia"47. Al derrotar al enemigo, el cristiano por tanto buscará sólo privarle de la capacidad para actuar violentamente. Otros actos de venganza hacia el enemigo, que eran típicos en el ejército romano en la época de Agustín, se sitúan fuera de los límites de la benevolencia, justicia y piedad, cuando estas virtudes se conciben como aspectos del amor de Dios.

Como dije, estas reflexiones a Marcelino sobre la conducta de guerra por parte de los cristianos, nos permite entender la diferencia que Agustín plantea en su carta a Macedonio entre el concepto convencional de paz en sus días, la pax Romana que se imponía con venganza sobre los pueblos conquistados, y el concepto de paz que está informado por la fe, la esperanza y la caridad cristianas, y en la que la moralidad de cada acción debe ser medida por la norma de un absoluto amor de Dios.

\footnotetext{
44 Ver Agustín, ep. 138.11.

45 Ver Agustín, ep. 138.12 .

46 Ver Agustín, ep. 138.12 .

47 Ver Agustín, ep. 138.14.
} 
He denominado a la discusión de Agustín en la epístola 155 sobre la transformación de las virtudes políticas a través de las virtudes teológicas una "teoría de la formación de la conciencia política" porque estoy convencido de que cumple esta función para Agustín. Macedonio, que se había opuesto inicialmente a la petición de clemencia en un caso de pena de muerte por parte de Agustín, se mostró más tarde capaz de seguir los complicados argumentos sobre la moralidad de la pena capital que Agustín le ofreció en la carta 153. Su última carta a Agustín demostró un alto grado de sensibilidad a la razón filosófica y a la sofisticada interpretación bíblica. Parece que, según los primeros párrafos de la carta 155, Agustín fue animado por la respuesta positiva de Macedonio a pasar de una discusión sobre la moralidad de la pena capital a un mayor desarrollo de las disposiciones que un estadista cristiano debe adquirir para tomar decisiones éticas en la esfera política. Creo que tenemos que tener en cuenta que Agustín nunca intentó imponer a Macedonio una posición contra la pena capital. He acentuado al interpretar la carta 153 que Agustín plantea ante el vicario imperial dos posiciones sobre el tema, insistiendo sólo en que los obispos no se equivocan en principio al interceder pidiendo clemencia en casos de importancia capital. Al contrario de algunos estudiosos que ofrecen interpretaciones de la correspondencia entre Agustín y Macedonio, no veo evidencias de que Agustín se dejara acobardar por este u otro oficial imperial. El rechazo de Agustín a imponer sus propios puntos de vista sobre Macedonio es produto, por el contrario, de su apreciación de la ambigüedad moral inherente a la cuestión sobre la pena capital. La solución que ofrece Agustín a Macedonio y a otras autoridades civiles con respecto a la ética política elude tanto el dogmatismo como el relativismo moral. Descansa, por el contrario, en la propia capacidad del oficial público para lo que Agustín llama "verdadera piedad" -la disciplina de permitir que el horizonte ético de alguien se amplíe por su amor a Dios más allá de una exclusiva preocupación por asegurar los beneficios temporales de la sociedad.

Quiero concluir admitiendo que existen problemas inherentes a la teoría de la formación de la conciencia política de Agustín tal y como la he presentado. Si la fe, la esperanza y la caridad deben convertirse en medios en la sociedad cristiana para repensar los conceptos de justicia y prudencia, uno se debe preguntar cuánto tiempo se necesita antes de que los obispos asuman el derecho a determinar el contenido de la fe, la esperanza y la caridad. La sombra de este problema aparece hacia el final de la epístola 155, cuando Agustín felicita a Macedonio por su persecución de los donatistas ${ }^{48}$.

${ }^{48}$ See Augustine, ep. 155.17. 
Al mismo tiempo, creo que es importante recordar que Agustín en ningún modo asigna un papel particular a los obispos para definir soluciones doctrinales a cuestiones sociales o políticas. Como obispo, Agustín tomó posiciones claras en un gran número de asuntos de ética social. No obstante, una enseñanza eclesial definida sobre cuestiones sociales, que pueda ser impuesta a los estadistas católicos como una cuestión de conciencia, se sitúa más allá de su horizonte eclesial. Más bien, la lógica fuerza de sus cartas a Macedonio se mueve en la dirección de guiar al vicario imperial en el desarrollo de su propia, autónoma, conciencia política bajo la influencia de la gracia.

Al mismo tiempo, creo que la insistencia de Agustín en la epístola 155 (una insistencia esbozada en la carta 138) de que aquellas virtudes políticas sólo son reales cuando son transformadas por una verdadera piedad se eleva contra la afirmación aún presente en nuestros días de que él anticipa la aparición de una razón política secular. La ética política fuera de las asunciones de la fe cristiana no podrían sostener la atención de Agustín por mucho tiempo. Es verdad que él juzgó algunos estadistas romanos capaces de ejercitar un mínimo de virtud, de poner entre paréntesis el propio interés lo justo para realizar ocasionalmente algunas obras virtuosas. No obstante, no creyó que la "virtud pagana", enraizada como lo estaba en una razón autónoma carente de la gracia, fuera duradera; ni siquiera que pudiera ser nunca paradigmática.

Para Agustín, sólo la religión cristiana ofrece concepciones de fe, esperanza y caridad capaces de guiar la ética política al servicio del bien común. En este caso no propugna un acercamiento religiosa o filosóficamente plural en el que la estricta adhesión a los principios cristianos es sacrificada en la búsqueda de un consenso político aceptable por todas las partes, cristianas o no. Más bien, Agustín fue políticamente realista, en el sentido en que no pretendió que el punto de vista cristiano prevaleciera en la esfera política de la sociedad del imperio romano tardío. Sin embargo, apremió a los oficiales públicos cristianos a gobernar con la sabiduría de Cristo haciéndose cada vez más como Cristo a través de la puesta en práctica de la fe, la esperanza y la caridad cristianas. La medida en que puedan realizarlo señalará la medida en la que el cristianismo pueda tener un impacto sobre la moralidad de la sociedad civil.

En conclusión, el intercambio epistolar entre Agustín y Macedonio (y Marcelino) muestra que Agustín enfatiza más el hecho de la conversión de los líderes políticos cristianos hacia la profundización de la fe, la esperanza y la caridad, que el hecho del influjo directo de los obispos sobre las decisiones que deben tomar los líderes políticos. El papel del obispo, según él, es formar la conciencia del oficial público a través de la enseñanza de la 
doctrina cristiana. Pero Agustín también muestra en esta correspondencia una simpatía por los problemas que los oficiales públicos cristianos afrontan para mantener la paz, la prosperidad y el orden públicos y en hacer respetar leyes justas. También comprende el contexto políticamente plural en el que estos oficiales deben gobernar. Aun cuando el cristianismo era la religión oficial del imperio romano, los principios morales cristianos estaban lejos de ser universalmente aceptados como base de gobierno. Agustín responde a estas dificultades que se presentan a los estadistas cristianos recurriendo al diálogo filosófico y teológico con ellos. Muestra respeto hacia sus argumentos incluso cuando no siempre está de acuerdo con ellos. Es consciente de que los obispos deben cultivar la estima e incluso, sí, la amistad con los oficiales públicos cristianos. Evita, por tanto, el uso de expresiones violentas en su discurso eclesiástico que seguramente constituyó una gran tentación para él, como seguramente ocurre a los obispos en nuestros días. 